\title{
BODIPY-Derived Piperazidine Fluorescent Near-Neutral PH Indicator and Its Bioimaging
}

Min Deng, Chengduan Yang, Deyan Gong, Anam Iqbal, Xiaoliang Tang, Weisheng Liu, and Wenwu Qin ${ }^{1}$

Key Laboratory of Nonferrous Metal Chemistry and Resources Utilization of Gansu

Province and State Key Laboratory of Applied Organic Chemistry, College of Chemistry and Chemical Engineering, Lanzhou University, Lanzhou 730000, P. R. China.

Two new 4,4-difluoro-4-bora-3a,4a-diaza-s-indacene (BODIPY) dyes (1 and 2) with piperazine subunits on position 3 or 5 were synthesized. Their absorption and steady-state fluorescence properties were investigated as a function of solvent. In water/MeCN $(9: 1, \mathrm{~V} / \mathrm{V})$ solution, the dyes show fluorescent enhancement upon increasing the acidity of the solution. They can be used in water/MeCN $(9: 1, \mathrm{~V} / \mathrm{V})$ solution as fluorescent $\mathrm{pH}$ probes excitable with visible light, with $\mathrm{p} K_{\mathrm{a}}$ values near-neutral (around 6.5 and 6.8). Dyes 1 and 2 are readily taken up by biological cells in the cytosol where it has no obvious toxic effects.

Keywords: BODIPY; piperazine; near-neutral pH; biological cells;

\footnotetext{
${ }^{1}$ Corresponding author: Fax: +86-931-8912582 E-mail address: qinww@1zu.edu.cn (W. Qin)
} 


\section{Introduction}

Fluorescent $\mathrm{pH}$ probes are obbligato tools for measuring changes of intracellular proton concentrations[1]. Measurement of $\mathrm{pH}$ by fluorescence-based technique is well established for both imaging and sensing applications[1, 2]. Compared to most other techniques, the fluorescence-based technique offers significant advantages owing to its generally nondestructive character, low background noise, high sensitivity and specificity, and the wide range of indicator dyes available[3-7]. To quantitatively determine $\mathrm{pH}$, it is imperative to match the $\mathrm{p} K_{\mathrm{a}}$ of the probe to the $\mathrm{pH}$ of the investigated system. Since the $\mathrm{pH}$ in the cytosol is close to neutral (generally between $\sim 6.8$ and 7.4), fluorescent probes with a $\mathrm{p} K_{\mathrm{a}}$ around 7 are necessary for cytosolic $\mathrm{pH}$ determinations.

Due to their excellent characteristics, 4,4-difluoro-4-bora-3a,4a-diaza-s-indacene[8-10] (better known as difluoroboron dipyrromethene or BODIPY) derivatives may be important beneficial fluorophores in the design of fluorescent sensors. The excellent qualities of BODIPY comprised relatively high fluorescence quantum yields and molar absorption coefficients, narrow emission bandwidths with high peak intensities, high elevated stability towards chemicals and light, and the extra feature of excitation / emission wavelengths in the visible region. Furthermore, the spectroscopic properties of BODIPY derivatives can be fine-tuned by synthetically introducing suitable substituents at the right positions of the BODIPY[8] core.

Difluoroboradiaza-s-indacenes with hydroxyaryl subunits have been reported as 
$\mathrm{pH}$ probes in aqueous-organic mixed media[11, 12]. These on / off $\mathrm{pH}$ probes showed a photo-induced electron transfer (PET) from the twisted and conjugatively uncoupled phenolate to the BODIPY subunit, causing fluorescence quenching at high $\mathrm{pH}$. 8-(4'-Hydroxyphenyl) substituted BODIPY derivatives[11] sense the alkaline $\mathrm{pH}$ range, while the tetrahydroxylated calix[4]arene derivative[12] is sensitive in the near-neutral $\mathrm{pH}$ range. In our previous work, we have synthesized and spectroscopically characterized two water-soluble, on/off $\mathrm{pH}$ indicators with $\mathrm{p} K_{\mathrm{a}}$ around 7.5 based on $o$-chlorophenol linked to the meso (8-) position[13, 14] or via a vinyl bridge to the 3-position[15] of BODIPY. A series of $\mathrm{pH}$ indicators based on BODIPY with meso-anilino substituents have been described recently for imaging acidic endosomes in cancer cells.[16] These derivatives are almost nonfluorescent in basic media due to PET.

We chose $\mathrm{N}$-methylpiperazine[17] and $\mathrm{N}$-ethylpiperazine with the favorable $\mathrm{p} K_{\mathrm{a}}$ around 9 to serve as $\mathrm{pH}$-sensitive ligand for the near-neutral $\mathrm{pH}$ range. Substitution of piperazidine will generally lead to altered the $\mathrm{p} K_{\mathrm{a}}$ values. Due to the electron-withdrawing character of BODIPY, it is expected that conjugatively linking BODIPY fluorescent reporter subunit via an ethenyl bridge to piperazidine will decrease the $\mathrm{p} K_{\mathrm{a}}$ of piperazidine in sensors $\mathbf{1}$ and $\mathbf{2}$ by approximately 1 unit compared to free piperazidine[18].

\section{Experimental section}

\subsection{Instrument and reagent}

All chemical solvents and reagent were obtained from Bailingwei. ${ }^{1} \mathrm{H}$ and ${ }^{13} \mathrm{C}$ 
NMR spectra were recorded with a Bruker DRX-400 and DRX-400/4 spectrometer with tetramethylsilane $(0.00 \mathrm{ppm})$ as an internal standard and $\mathrm{CDCl}_{3}$ as solvent. Chemical shift multiplicities are reported as $\mathrm{s}=$ singlet, $\mathrm{d}=$ doublet, $\mathrm{t}=$ triplet, $\mathrm{q}=\mathrm{quartet}$ and $\mathrm{m}=$ multiplet. ${ }^{13} \mathrm{C}$ spectra were referenced to ppm with the $\mathrm{CDCl}_{3}(77.67 \mathrm{ppm})$ signal. Mass spectra were recorded in E.I. mode. Melting points were obtained with an X-4 precise micro melting point cryoscope (Beijing Fukai Instrument Co.) and are uncorrected. All measurements were performed at room temperature.

\subsection{The synthesis of sensor 1}

BODIPY derivatives $\mathbf{1}$ and $\mathbf{2}$ were prepared using the same procedure, starting from 3,5-dichloro-4,4-difluoro-8-(4-tolyl)-4-bora-3a,4a-diaza-s-indacene (3).

The synthetic route is depicted in Scheme $1.150 \mathrm{mg}(0.43 \mathrm{mmol})$ of compound 3 was dissolved in $25 \mathrm{ml}$ acetonitrile and $0.5 \mathrm{ml}$ of triethylamine was added to it. After 15 minutes, $48 \mu \mathrm{l}(0.43 \mathrm{mmol})$ of compound $\mathrm{N}$-methylpiperazine was added to it. The reaction mixture was stirred at room temperature for $72 \mathrm{~h}$. After solvent was removed under reduced pressure, the crude solid was purified by column chromatography on silica purified through column chromatography over silica (dichloromethane/methanol, 50/1, v/v) to obtain a reddish brown powder $130 \mathrm{mg}$ of $\mathbf{1}$ with $75 \%$ yield. Reddish solid, mp 127-128 ${ }^{\circ} \mathrm{C} ;{ }^{1} \mathrm{H} \mathrm{NMR}\left(\mathrm{CDCl}_{3}, 400 \mathrm{MHz}\right) \delta 2.36$ (s, 3H, H-a), 2.41 (s, 3H, H-b), 2.63 (t, 4H, J = $4.8 \mathrm{~Hz}, \mathrm{H}-\mathrm{c}$ ), 3.99 (t, 4H, J = $4.8 \mathrm{~Hz}$, H-d), 6.18 (d, 1H, J = 4.0 Hz, H-e), 6.246 (d, 1H, $J=5.2 \mathrm{~Hz}, \mathrm{H}-\mathrm{g}), 6.28$ (d, 1H, $J=$ $4.0 \mathrm{~Hz}, \mathrm{H}-\mathrm{f}), 6.848$ (d, 1H, J = 5.2 Hz, H-h), 7.22 (d, 2H, J = 8.0 Hz, aromatic), 7.29 (d, $2 \mathrm{H}, J=8.0 \mathrm{~Hz}$, aromatic); ${ }^{13} \mathrm{C} \mathrm{NMR}\left(\mathrm{CDCl}_{3}, 100 \mathrm{MHz}\right): \delta 21.45,45.74,50.29$, 
$54.96,113.03,113.72,119.02,128.98,129.50,130.46,131.35,131.45,131.55$, 135.15, 135.64, 139.26, 162.01; MS (ESI) $\mathrm{m} / \mathrm{z}$ calcd. For $\mathrm{C}_{21} \mathrm{H}_{22} \mathrm{BClF}_{2} \mathrm{~N}_{4}$ 414.2; found $415.2(\mathrm{M}+1) ; 395.2(\mathrm{M}-\mathrm{F}, 100 \%)$.

\subsection{The synthesis of sensor 2}

The crude solid was purified by column chromatography on silica purified through column chromatography over silica (dichloromethane/methanol, 50/1, v/v) to obtain a reddish brown powder $135 \mathrm{mg}$ of $\mathbf{2}$ with $73 \%$ yield. Reddish solid, mp 150-152 ${ }^{\circ} \mathrm{C} ;{ }^{1} \mathrm{H}$ NMR $\left(\mathrm{CDCl}_{3}, 400 \mathrm{MHz}\right) \delta 1.12(\mathrm{t}, 3 \mathrm{H}, \mathrm{J}=7.2 \mathrm{~Hz}, \mathrm{H}-\mathrm{a}$ '), $2.41(\mathrm{~s}, 3 \mathrm{H}$, H-b), 2.49 (q, 2H, J = 7.2 Hz, H-a), 2.67 (t, 4H, J = 4.8 Hz, H-c), 4.00 (t, 4H, J = 4.8 Hz, H-d), 6.177 (d, 1H, J = 4.0 Hz, H-e), 6.25 (d, 1H, J = 5.2 Hz, H-g), 6.27 (d, 1H, $J$ $=4.0 \mathrm{~Hz}, \mathrm{H}-\mathrm{f}), 6.844(\mathrm{~d}, 1 \mathrm{H}, J=5.2 \mathrm{~Hz}, \mathrm{H}-\mathrm{h}), 7.22(\mathrm{~d}, 2 \mathrm{H}, J=8.0 \mathrm{~Hz}$, aromatic $)$,

$7.29\left(\mathrm{~d}, 2 \mathrm{H}, J=8.0 \mathrm{~Hz}\right.$, aromatic); ${ }^{13} \mathrm{C} \mathrm{NMR}\left(\mathrm{CDCl}_{3}, 100 \mathrm{MHz}\right): \delta 11.87,21.44$, 50.41, 52.13, 52.80, 112.94, 113.78, 118.80, 128.96, 129.29, 130.46, 131.27, 131.34, 131.49, 135.20, 135.60, 139.20, 161.91; MS (ESI) $\mathrm{m} / z$ calcd. For $\mathrm{C}_{22} \mathrm{H}_{24} \mathrm{BClF}_{2} \mathrm{~N}_{4}$ 428.2; found $429.2(\mathrm{M}+1,100 \%)$.

\section{< Scheme 1>}

\subsection{Determination of $K_{a}$ from Direct Fluorimetric Titration}

The $K_{\mathrm{a}}$ values of $\mathbf{1}$ and $\mathbf{2}$ were determined in water/MeCN $(9: 1, \mathrm{~V} / \mathrm{V})$ solution at 25 ${ }^{\circ} \mathrm{C}$ by direct fluorometric titration as a function of $\mathrm{pH}$ using the fluorescence emission spectra. Nonlinear fitting of Eq.1[19, 20] to the steady-state fluorescence data $F$ recorded as a function of $\left[\mathrm{H}^{+}\right]$yields values of $K_{\mathrm{a}}$, the fluorescence signals $F_{\min }$ and $F_{\max }$ 
at minimal and maximal $\left[\mathrm{H}^{+}\right]$, respectively, and $n$ (the number of protons bound per fluorescent $\mathrm{pH}$ probe).

$$
F=\frac{F_{\max }\left[\mathrm{H}^{+}\right]^{n}+F_{\min } K_{\mathrm{a}}}{K_{\mathrm{a}}+\left[\mathrm{H}^{+}\right]^{n}}
$$

Because the fits of Eq. 1 to the fluorescence data $F$ with $n, K_{\mathrm{a}}, F_{\min }$, and $F_{\max }$ as freely adjustable parameters always gave values of $n$ close to $1, n$ was kept fixed at 1 in the final curve fittings, from which the estimated values of $K_{\mathrm{a}}$ are reported here. Equation 1 assumes (i) photo-excitation with light of constant incident spectral radiant power, (ii) that the absorbance $A$ of the sample is small $(\leq 0.1)$ and (iii) the rate of proton binding in the excited state can be neglected.

\subsection{General method for measurements of photophysical properties}

UV-vis absorption spectra were recorded on a Varian UV-Cary 5000 spectrophotometer and for the corrected steady-state emission spectra, a Hitachi F-7000 spectrofluorimeter was employed. Freshly prepared samples were used to perform all UV-vis absorption and emission measurements. For the determination of the fluorescence quantum yields $\phi_{\mathrm{f}}$ of $\mathbf{1}$ and $\mathbf{2}$, only dilute solutions with an absorbance below 0.1 at the excitation wavelength $\left(\lambda_{\mathrm{ex}}=480 \mathrm{~nm}\right)$ were used. Rhodamine $6 \mathrm{G}$ in water $\left(\phi_{\mathrm{f}}=0.76\right)$ was used as fluorescence standard [21]. The $\phi_{\mathrm{f}}$ values reported in this work are the averages of multiple (generally three), fully independent measurements. In all cases, correction for the solvent refractive index was applied.

All measurements were done at $25{ }^{\circ} \mathrm{C}$ with an air conditioner. 


\subsection{Crystal structure determination}

Crystals of $\mathbf{1}$ were obtained by slow evaporation of the mixed solvent (dichloromethane/cyclohexane) $(2: 1, \mathrm{v} / \mathrm{v})$ in air over one weeks, yielding clear dark orange block crystals with approximate dimensions of $0.18 \times 0.14 \times 0.11 \mathrm{~mm}^{3}$ suitable for X-ray diffraction.

Crystals of 2 were obtained by slow evaporation of the ethyl acetate in air over two weeks, yielding clear dark violet block crystals with approximate dimensions of $0.34 \times 0.32 \times 0.31 \mathrm{~mm}^{3}$ suitable for X-ray diffraction. The basic crystallographic data of $\mathbf{1}$ and $\mathbf{2}$ are compiled in Table S1.

The data for $\mathbf{1}$ and $\mathbf{2}$ was measured on a Bruker Smart APEX II CCD diffractometer at $155 \pm 10 \mathrm{~K}$ and $297 \pm 10 \mathrm{~K}$ respectively equipped with graphite-monochromatized Mo $K \alpha$ radiation $(\lambda=0.71073 \AA$ and $\lambda=1.54184 \AA)$. The structures were solved by direct methods. All non-hydrogen atoms were subjected to anisotropic refinement by full-matrix least-squares methods on $F^{2}$ by using the program package SHELXS-97[22]. Hydrogen atoms were placed at calculated positions.

Crystallographic data (excluding structure factors) for the structure reported in this paper have been deposited with the Cambridge Crystallographic Data Centre as supplementary publication no. CCDC 1443775 for $\mathbf{1}$ and CCDC 1443776 for 2. Copies of the data can be obtained free of charge on application to CCDC, 12 Union Road, Cambridge CB2 1EZ, U.K. (fax: $+44(0)-1223-336033$ or e-mail: deposit@ccdc.cam.ac.uk or www.ccdc.cam.ac.uk/conts/retrieving.html). 


\subsection{Cell culture, fluorescence imaging and cytotoxicity assay}

Cell Culture and fluorescence imaging. To determine the cell permeability of $\mathbf{1}$ or 2, Baby Hamster Syrian Kindey (BHK) cells were cultured in DMEM (Dulbecco's Modified Eagle Medium) supplemented with 10\% FBS (fetal bovine serum). The cell lines were maintained in a humidified atmosphere containing $5 \% \mathrm{CO}_{2}$ at $37{ }^{\circ} \mathrm{C}$. After removal of the culture medium, cells were incubated with 1 or $2(10 \mu \mathrm{M})$ in $1.0 \mathrm{~mL}$ of fresh culture medium for $2 \mathrm{~h}$. Before imaging measurement, the cells were washed three times with PBS to remove the residual 1 or $\mathbf{2}$. Cells were observed under an Olympus FV1000-IX81 laser confocal microscope.

Cytotoxicity Test. BHK Cells were seeded at a density of $10^{4}$ cells per well (100 $\mu \mathrm{L}$ total volume/well) in 96 -well assay plates for $24 \mathrm{~h}$. Then, the as-prepared $\mathbf{1}$ or $\mathbf{2}$, at the indicated concentrations $(0,5,10,15,20,25 \mu \mathrm{g} / \mathrm{ml})$, were added to the cell culture medium. Cells were incubated with 1 or 2 for 24 h. To determine toxicity, 3-(4,5-Dimethylthiazol-2-yl)-5-(3-carboxymethoxyphenyl)-2-(4-sulfophenyl)-2H-tetr azolium, inner salts (MTS) was added to each well of the microtiter plate and the plate was incubated in the $\mathrm{CO}_{2}$ incubator for additional $4 \mathrm{~h}$. Absorbance values were determined with Bio-Rad model-680 microplate reader at $490 \mathrm{~nm}$ (corrected for background absorbance at $630 \mathrm{~nm}$ ). The cell viability was estimated according to the following equation: cell viability $(\%)=$ mean of absorbance value of treatment group/mean absorbance value of control $\times 100 \%$.

\subsection{Theoretical calculations}

The calculation was performed using the Gaussian 09 suite of programs[23]. The 
ground state structures of two compounds were based on the corresponding crystal structures and were not further optimized. The density functional theory (DFT) with Becke's three parameter hybrid functional with the Lee-Yang-Parr correlation functional (B3LYP) and 6-31+G(d) basis set were used to treat all atoms. The excited state related calculations were carried out with the time dependent density functional theory (TD-DFT) with the ground state structure was obtained. There are no imaginary frequencies in frequency analysis, and the contours of the HOMOs and LUMOs were plotted to understand the nature of the excited state. The energy and oscillator strength for the twenty lowest singlet-singlet absorptions of each compound were obtained from the TD-DFT output files. The calculated absorption spectra were visualized directly with Gauss View 5.0.

\section{Results and Discussion}

\subsection{Crystal structure of $\mathbf{1}$ and $\mathbf{2}$.}

As shown in Figure 1, the two planar pyrrole subunits and the boron atom constitute a plane for which the deviation of all non-hydrogen atoms is within the 0.005-0.070 $\AA$ range in the BODIPY ring system. The angle between the two pyrrole moieties is $10.43^{\circ}$ (for $\mathbf{1}$ ) and $7.45^{\circ}$ (for 2), which is near the average $5.79^{\circ}$ (range $0^{\circ}-18.1^{\circ}$ ) found in the Cambridge Structural Database (CSD, updated to October 2008). The two fluorine atoms are equidistant above and under the plane of the pyrrole moieties, and the $\mathrm{F}-\mathrm{B}-\mathrm{F}$ plane is $109.91^{\circ}$ (for $\mathbf{1}$ ) and $110.07^{\circ}$ (for 2)to the plane of the BODIPY core. The methyl phenyl ring at the meso-position makes an angle of $54.79^{\circ}$ (for 1) and $60.41^{\circ}$ (for 2) with the BODIPY plane, which is in the 
range of most BODIPY derivatives $\left(40.3^{\circ}-90^{\circ}\right)$, but is smaller than the average value of $76.4^{\circ}$ found in the CSD. The dihedral angles between piperzine ring and pyrroles is $41.15^{\circ}$ (for $\mathbf{1}$ ) and $41.80^{\circ}$ (for 2 ).

\section{< Fig. 1 >}

\subsection{Spectroscopic properties 1 and 2 .}

Sensors $\mathbf{1}$ and $\mathbf{2}$ were dissolved in several solvents respectively (cyclohexane, THF, MeCN) to investigate their solvatochromic properties. Figure 2 shows the normalized UV-vis absorption and fluorescence emission spectra of $\mathbf{1}$ dissolved in various solvents. The absorption spectrum is of comparable shape as those of the described BODIPY dyes[24-28], with an intense absorption band somewhat above $470 \mathrm{~nm}$ (is attributed to the $0-0$ vibrational band of $S_{0} \rightarrow S_{1}$ transition) in acetonitrile. Additionally, a weaker, broad band is found in the absorption spectra at around 340 $\mathrm{nm}$. This broader and weaker absorption band is attributed to the $0-0$ vibrational band of $S_{0} \rightarrow S_{2}\left(\pi-\pi^{*}\right)$ transition. The main absorption band of 1 is at $\sim 515 \mathrm{~nm}$ in cyclohexane, and a shoulder at the short wavelength side can be observed - centered at approximately $490 \mathrm{~nm}$ - which is assigned to the $0-1$ vibrational band of the same transition. In more polar solvents no vibrational fine structure can be observed. The absorption spectra of $\mathbf{2}$ (Fig S1) is, in general, similar to those of $\mathbf{1}$ in the solvents used.

The probes $\mathbf{1}$ or $\mathbf{2}$ in various solvents shows an emission spectrum with a maximum at $\sim 550 \mathrm{~nm}$, shaped like the mirror image of the absorption spectrum, displaying the typical emission features of BODIPY[24-28]. The $\phi_{\mathrm{f}}$ value for $\mathbf{1}$ and $\mathbf{2}$ are low in 
solvents (about 0.05) can be attributed to an efficient quenching via an excited-state ICT process from the nitrogen atom of piperazine to the strongly electron-deficient BODIPY acceptor. The absorption spectra are affected by solvent polarity; the maximum being blue-shifted (by $\sim 44 \mathrm{~nm}$ ) when the solvent is changed from cyclohexane $(518 \mathrm{~nm})$ to acetonitrile $(474 \mathrm{~nm})$. The maximum wavelength of the fluorescence band is hardly affected by solvent polarity (Figure 2, Table 1): there is only a $7 \mathrm{~nm}$ difference between the wavelengths of the emission maxima $\lambda_{\mathrm{em}}(\max )$ in toluene $(560 \mathrm{~nm})$ and DMSO $(553 \mathrm{~nm})$. The blue shift of the absorption spectrum from cyclohexane to acetonitrile can hardly be attributed to a difference in solvent polarizability (Figure S2). If it is attributed to dipolar interactions, this blue shift suggests that the dipole moment of the ground state is larger than that of the excited state.[29]

\section{< Fig. 2>}

\section{$<$ Table 1>}

\subsection{Fluorimetric titrations of $\mathbf{1}$ and $\mathbf{2}$.}

Protonation of the piperazine function drastically alters the electron-donating properties of the tertiary amine group and consequently it is expected to switch off the ICT to the borondipyrromethene moiety. The changes of the absorption spectra of $\mathbf{1}$ as a function of $\mathrm{pH}$ are shown in Figure 3a. It is clear that changing the $\mathrm{pH}$ leads to several isosbestic points and is accompanied by a hypsochromic shift of the major absorption maximum of 1 (from $485 \mathrm{~nm}$ at $\mathrm{pH} 3.36$ to $474 \mathrm{~nm}$ at $\mathrm{pH} 8.86$ ) upon increasing the $\mathrm{pH}$. 
The fluorescence emission spectra of $\mathbf{1}$ in water/MeCN $(9: 1, \mathrm{~V} / \mathrm{V})$ solution are shown as a function of $\mathrm{pH}$ in Figures 3c. The fluorescence signals increase considerably at lower $\mathrm{pH}$. The highest $\phi_{\mathrm{f}}$ value $\left(0.12, \lambda_{\mathrm{ex}}=480 \mathrm{~nm}\right)$ is found at low $\mathrm{pH}(\mathrm{pH} 3.22)$. Binding of $\mathrm{H}^{+}$by the piperazine raises the energy of the intramolecular CT state and hence suppresses the formation of this state. Blocking this non-radiative decay channel of the locally excited state leads to a large fluorescence enhancement.

Analogous absorption effects are found for 2 (Figure $3 b$ ), where the major absorption maximum shifts hypsochromically from $485 \mathrm{~nm}$ at $\mathrm{pH} 3.72$ to $474 \mathrm{~nm}$ at $\mathrm{pH}$ 8.68. In analogy to $\mathbf{1}$, the fluorescence emission maximum at $\sim 550 \mathrm{~nm}$ of 2 remains almost unaffected by $\mathrm{pH}$ (Figure 3d). The fluorescence intensity increases significantly with decreasing $\mathrm{pH}$. The highest $\phi_{\mathrm{f}}$ value $\left(0.13, \lambda_{\mathrm{ex}}=480 \mathrm{~nm}\right)$ is found at low $\mathrm{pH}(\mathrm{pH} 3.82)$. Figure $\mathrm{S} 3$ and $\mathrm{S} 4$ displays the absorption and emission spectra of sensors 1 and 2 as a function of $\mathrm{pH}(7-12)$ in water/MeCN $(9: 1, \mathrm{~V} / \mathrm{V})$ solution. In alkaline conditions, the absorption and emission spectra hardly be influenced by $\mathrm{pH}$ in the range of 8-12.

\section{$<$ Fig. 3>}

The acidity constant $K_{\mathrm{a}}$ and the stoichiometry $(n)$ of the binding of $\mathrm{H}^{+}$by the piperazine (tertiary amine) group of new fluorescent $\mathrm{pH}$ indicators in water/MeCN $(9: 1, \mathrm{~V} / \mathrm{V})$ solution were determined by fitting eq 1 to the fluorescence emission spectral data. The results of the direct fluorimetric titration using the emission data of Figure $3 \mathrm{c}\left(\lambda_{\mathrm{ex}}=480 \mathrm{~nm}, \lambda_{\mathrm{em}}=550 \mathrm{~nm}\right)$ are displayed in Figure $4 \mathrm{a}$ and yield a $\mathrm{p} K_{\mathrm{a}}$ value of $6.45 \pm 0.05$ and a well-defined 1:1 stoichiometry between 1 and $\mathrm{H}^{+}$, indicate 
the formation of indicative of ammonium ion. A similar titration using the emission spectra of Figure $3 \mathrm{~d}\left(\lambda_{\mathrm{ex}}=480 \mathrm{~nm}, \lambda_{\mathrm{em}}=550 \mathrm{~nm}\right)$ yield a $\mathrm{p} K_{\mathrm{a}}$ value of $6.74 \pm 0.11$ and a well-defined 1:1 stoichiometry between 2 and $\mathrm{H}^{+}$(figure $4 \mathrm{~b}$ ). These results are in perfect agreement with the curve-fittings using different wavelength of sensor $\mathbf{1}$

(Fig S5, at $535 \mathrm{~nm}: \mathrm{p} K_{\mathrm{a}}=6.43 \pm 0.06$, at $555 \mathrm{~nm}: \mathrm{p} K_{\mathrm{a}}=6.52 \pm 0.06$ ) and sensor 2 (Fig S6 at 530nm: $\mathrm{p} K_{\mathrm{a}}=6.73 \pm 0.08$ at $\left.560 \mathrm{~m}: \mathrm{p} K_{\mathrm{a}}=6.88 \pm 0.15\right)$. The average $\mathrm{p} K_{\mathrm{a}}$ obtained from Fig S7 are $6.50 \pm 0.07(\mathbf{1})$ and $6.80 \pm 0.11(2)$. These results show that the obtained $\mathrm{p} K_{\mathrm{a}}$ values are independent of the selected wavelengths. All estimated $n$ values are indicative of a 1 to 1 binding between dyes $\mathbf{1}$ or $\mathbf{2}$ and $\mathrm{H}^{+}$.

\section{< Fig. 4>}

\subsection{Cell culture}

For practical applications, it is necessary that the molecular probe described here is able to detect $\mathrm{pH}$ under biological conditions. To test whether $\mathbf{1}$ or $\mathbf{2}$ fulfills these additional requirements, measurements on live cells were performed. Based on the fluorescence intensity upon excitation at $488 \mathrm{~nm}$ of the BHK cells during dye loading $(10 \mu \mathrm{M})$, it can be concluded that $\mathbf{1}$ or $\mathbf{2}$ efficiently accumulates inside the cytosol, but is excluded from the cell nucleus (Fig. 5).

Moreover, cell cytotoxicity experiment of $\mathbf{1}$ or $\mathbf{2}$ was evaluated using BHK cell lines through the MTS assay. As shown in Fig S9, the $\mathbf{1}$ and $\mathbf{2}$ exhibited low cytotoxicity, which may be due to the low toxicity of BODIPY. Taken together, it is clearly demonstrated that the sensor is membrane-permeable, and the fluorescence change in the BHK cells was due to the synchronous presence of $\mathbf{1}$ and $\mathbf{2}$. The result 
confirmed that the probe $\mathbf{1}$ or $\mathbf{2}$ can be used to image intracellular $\mathrm{pH}$ levels in living cells.

\section{$\langle$ Fig. 5>}

\section{Conclusion}

We have synthesized two new 4,4-difluoro-4-bora-3a,4a-diaza-s-indacene dyes (1-2) with piperazine subunits. Their absorption and steady-state fluorescence properties were investigated as a function of solvent. In water/MeCN (9:1, V/V) solution, the dyes $\mathbf{1}$ and $\mathbf{2}$ undergo a reversible protonation-deprotonation reaction in the near-neutral $\mathrm{pH}$ range. They can be used in water/MeCN $(9: 1, \mathrm{~V} / \mathrm{V})$ solution as fluorescent $\mathrm{pH}$ probes excitable with visible light, with $\mathrm{p} K_{\mathrm{a}}$ values were $6.5 \pm 0.07$ and 6.8 \pm 0.11 . For cytosolic $\mathrm{pH}$ measurements, a better match between the $\mathrm{p} K_{\mathrm{a}}$ of the indicator and $\mathrm{pH}(6.8-7.4)$ is desirable. Dyes $\mathbf{1}$ and $\mathbf{2}$ are readily taken up by biological cells in the cytosol where it is no obvious toxic effects.

\section{Acknowledgments}

The authors would like to thank the Natural Science Foundation of China (no. 21271094, 21371083). This work was supported by the National Science Foundation for Fostering Talents in Basic Research of the National Natural Science Foundation of China (Grant no. J1103307).

\section{Supporting Information Available:}

Compound characterization data, this material can be found in the Supporting Information. 


\section{References}

[1] R.P. Haugland, The handbook: a guide to fluorescent probes and labeling technologies: Molecular probes. 2005.

[2] J. Han, K. Burgess, Fluorescent indicators for intracellular pH, Chem. Rev. 110(2009) 2709-2728.

[3] J.-P. Desvergne, A.W. Czarnik, Chemosensors of ion and molecule recognition: Springer. Berlin. 1997.

[4] X. Li, X. Gao, W. Shi, H. Ma, Design strategies for water-soluble small molecular chromogenic and fluorogenic probes, Chem. rev. 114(2013) 590-659.

[5] G.K. Vegesna, J. Janjanam, J. Bi, F.-T. Luo, J. Zhang, C. Olds, et al., pH-activatable near-infrared fluorescent probes for detection of lysosomal pH inside living cells, J. Mater. Chem. B. 2(2014) $4500-4508$.

[6] Q. Wan, S. Chen, W. Shi, L. Li, H. Ma, Lysosomal pH Rise during Heat Shock Monitored by a Lysosome - Targeting Near - Infrared Ratiometric Fluorescent Probe, Angew. Chem. 126(2014) 11096-11100.

[7] L. Fan, Q. Liu, D. Lu, H. Shi, Y. Yang, Y. Li, et al., A novel far-visible and near-infrared pH probe for monitoring near-neutral physiological $\mathrm{pH}$ changes: imaging in live cells, J. Mater. Chem. B. $1(2013) 4281-4288$.

[8] A. Treibs, F.H. Kreuzer, Difluorboryl - Komplexe von Di - und Tripyrrylmethenen, Liebigs Ann. Chem. 718(1968) 208-223.

[9] A. Loudet, K. Burgess, BODIPY dyes and their derivatives: syntheses and spectroscopic properties, Chem. Rev. 107(2007) 4891-4932. 
[10] G. Ulrich, R. Ziessel, A. Harriman, The chemistry of fluorescent bodipy dyes: versatility unsurpassed, Angew. Chem., Int. Ed. 47(2008) 1184-1201.

[11] T. Gareis, C. Huber, O.S. Wolfbeis, J. Daub, Phenol/phenolate-dependent on/off switching of the luminescence of 4, 4-difluoro-4-bora-3a, 4a-diaza-s-indacenes, Chem. Commun. (1997) 1717-1718.

[12] C.N. Baki, E.U. Akkaya, Boradiazaindacene-appended calix [4] arene: fluorescence sensing of pH near neutrality, J. org. chem. 66(2001) 1512-1513.

[13] M. Baruah, W. Qin, N. Basaric, W.M. De Borggraeve, N. Boens, BODIPY-based hydroxyaryl derivatives as fluorescent pH probes, J org chem, 70(2005) 4152-4157.

[14] W. Qin, M. Baruah, A. Stefan, M. Van der Auweraer, N. Boens, Photophysical Properties of BODIPY - Derived Hydroxyaryl Fluorescent pH Probes in Solution, ChemPhysChem. 6(2005) 2343-2351.

[15] W. Qin, M. Baruah, W.M. De Borggraeve, N. Boens, Photophysical properties of an on/off fluorescent $\mathrm{pH}$ indicator excitable with visible light based on a borondipyrromethene-linked phenol, J Photochem. Photobiol., A. 183(2006) 190-197.

[16] Y. Urano, D. Asanuma, Y. Hama, Y. Koyama, T. Barrett, M. Kamiya, et al., Selective molecular imaging of viable cancer cells with pH-activatable fluorescence probes, Nat. med. 15(2009) 104-109.

[17] A. Castro, J.R. Leis, M.E. Peña, Decomposition of N-methyl-N-nitrosotoluene-p-sulphonamide in basic media: hydrolysis and transnitrosation reactions, J. Chem. Soc., Perkin Trans. 2. (1989) 1861-1866.

[18] N. Boens, W. Qin, M. Baruah, W.M. De Borggraeve, A. Filarowski, N. Smisdom, et al., Rational Design, Synthesis, and Spectroscopic and Photophysical Properties of a Visible - Light - Excitable, Ratiometric, Fluorescent Near - Neutral pH Indicator Based on BODIPY, Chem.-Eur. J. 17(2011) 
10924-10934.

[19] E. Cielen, A. Tahri, K. Ver Heyen, G.J. Hoornaert, F.C. De Schryver, N. Boens, Synthesis and spectroscopic characterisation of fluorescent indicators for $\mathrm{Na}^{+}$and $\mathrm{K}^{+}, \mathrm{J}$. Chem. Soc., Perkin Trans. 2. (1998) 1573-1580.

[20] E. Cielen, A. Stobiecka, A. Tahri, G.J. Hoornaert, F.C. De Schryver, J. Gallay, et al., Synthesis and characterisation of Thio- $\mathrm{H}$, a new excitation and emission ratioable fluorescent $\mathrm{Ca}^{2+} / \mathrm{Mg}^{2+}$ indicator with high brightness, J. Chem. Soc., Perkin Trans. 2. (2002) 1197-1206.

[21] J. Olmsted, Calorimetric determinations of absolute fluorescence quantum yields, J. Phys. Chem. 83(1979) 2581-2584.

[22] G. Sheldrick, SHELX-97, Program for crystal structure solution and refinement, University of Göttingen, Germany, (1997) 1456.

[23] M. Frisch, G. Trucks, H. Schlegel, G. Scuseria, M. Robb, J. Cheeseman, et al., Gaussian 09, revision A. 1; Gaussian, Inc: Wallingford, CT. 2009.

[24] T.L. Arbeloa, F.L. Arbeloa, I.L. Arbeloa, I. Garcia-Moreno, A. Costela, R. Sastre, et al., Correlations between photophysics and lasing properties of dipyrromethene- $\mathrm{BF}_{2}$ dyes in solution, Chem. Phys. Lett. 299(1999) 315-321.

[25] A. Costela, I. García-Moreno, C. Gomez, R. Sastre, F. Amat-Guerri, M. Liras, et al., Photophysical and lasing properties of new analogs of the boron-dipyrromethene laser dye PM567 in liquid solution, J. Phys. Chem. A. 106(2002) 7736-7742.

[26] V.M. Martınez, F.L. Arbeloa, J.B. Prieto, T.A. López, I.L. Arbeloa, Characterization of rhodamine 6G aggregates intercalated in solid thin films of laponite clay. 1. Absorption spectroscopy, J. Phys.

Chem. B. 108(2004) 20030-20037. 
[27] V. Leen, V.Z. Gonzalvo, W.M. Deborggraeve, N. Boens, W. Dehaen, Direct functionalization of BODIPY dyes by oxidative nucleophilic hydrogen substitution at the 3- or 3,5-positions, Chem. Commun. 46(2010) 4908-4910.

[28] A. Filarowski, M. Lopatkova, P. Lipkowski, M. Van der Auweraer, V. Leen, W. Dehaen, Solvatochromism of BODIPY-Schiff Dye, J. Phys. Chem. B. 119(2014) 2576-2584.

[29] W. Qin, V. Leen, T. Rohand, W. Dehaen, P. Dedecker, M. Van der Auweraer, et al., Synthesis, spectroscopy, crystal structure, electrochemistry, and quantum chemical and molecular dynamics calculations of a 3-anilino difluoroboron dipyrromethene dye, J. Phys. Chem. A. 113(2008) 439-447.

\section{Figure captions}

Fig. 1. ORTEP representation of compounds 1 (a) and 2 (b) with displacement ellipsoids at the $20 \%$ probability level.

Fig. 2: Normalized absorption (dash curves) and fluorescence spectra (solid curves) of sensor $\mathbf{1}$ in various solvents.

Fig. 3: Absorption spectra of sensors 1 (a) and 2 (b) in water/MeCN (9:1, V/V) solution as a function of $\mathrm{pH}$. Corresponding fluorescence emission spectra $\mathrm{c}$ and $\mathrm{d}$. $\left(\lambda_{\mathrm{ex}}=480 \mathrm{~nm}\right)$.

Fig. 4: The solid line represents the best fit of eq 1 with $n=1$ to the fluorimetric titration data of sensors 1 (a) and $\mathbf{2}$ (b) obtained from the emission spectra of Figure $3 \mathrm{c}$ and $3 \mathrm{~d}\left(\lambda_{\mathrm{ex}}=480 \mathrm{~nm}\right)$. 
Fig. 5: Confocal fluorescence images of BHK cells of the sensors $\mathbf{1}$ and $\mathbf{2}$. The bright-field images of $\mathbf{1}$ (a) and $\mathbf{2}$ (c); the confocal fluorescence images of $\mathbf{1}$ (b) and $\mathbf{2}$ (d).

Table 1. Spectroscopic / Photophysical Data of sensors 1 and 2 in Different Solvents at $25^{\circ} \mathrm{C}$.

Scheme 1. Synthesis of sensors 1 and 2.

Fig. 1
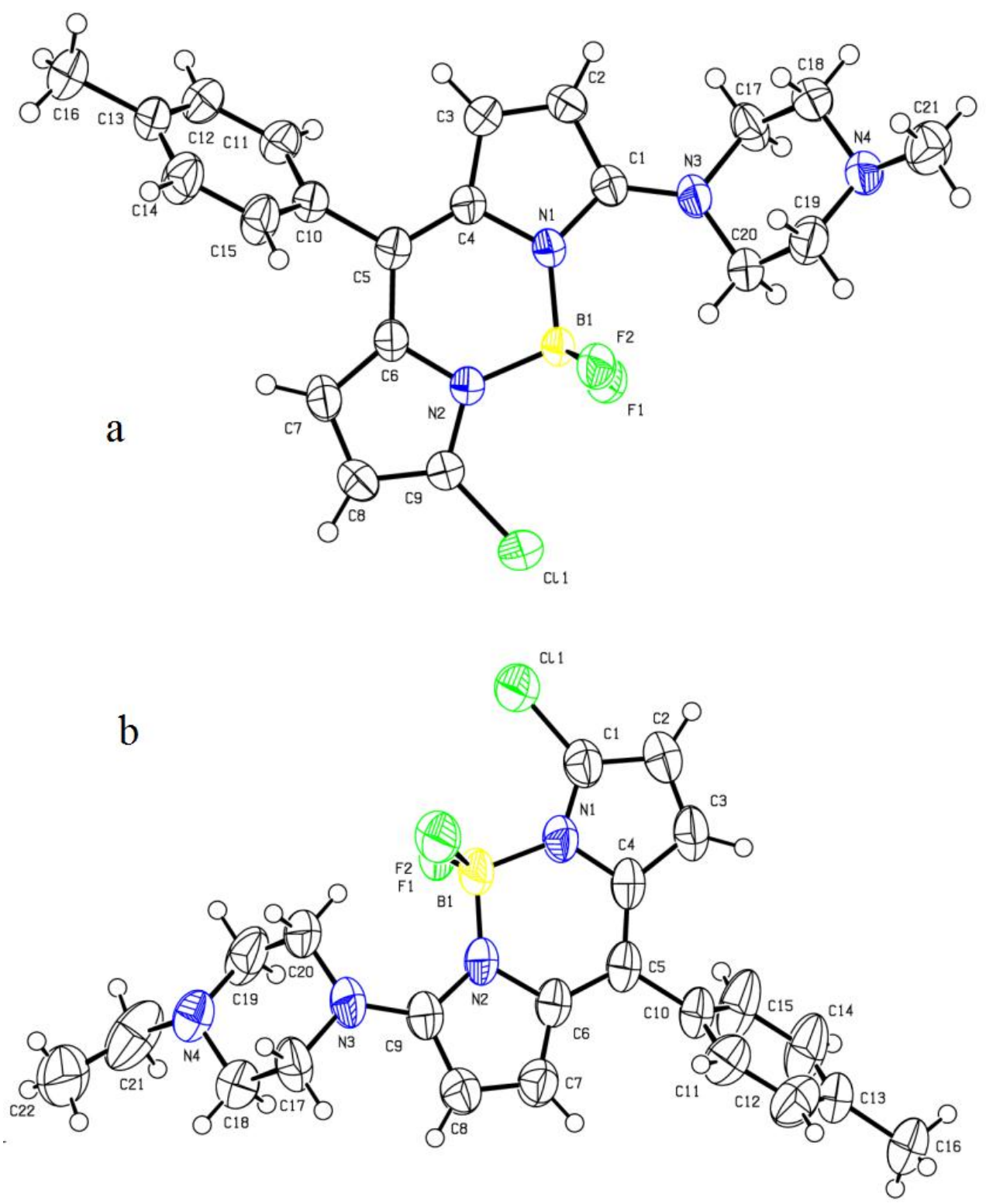
Fig. 2

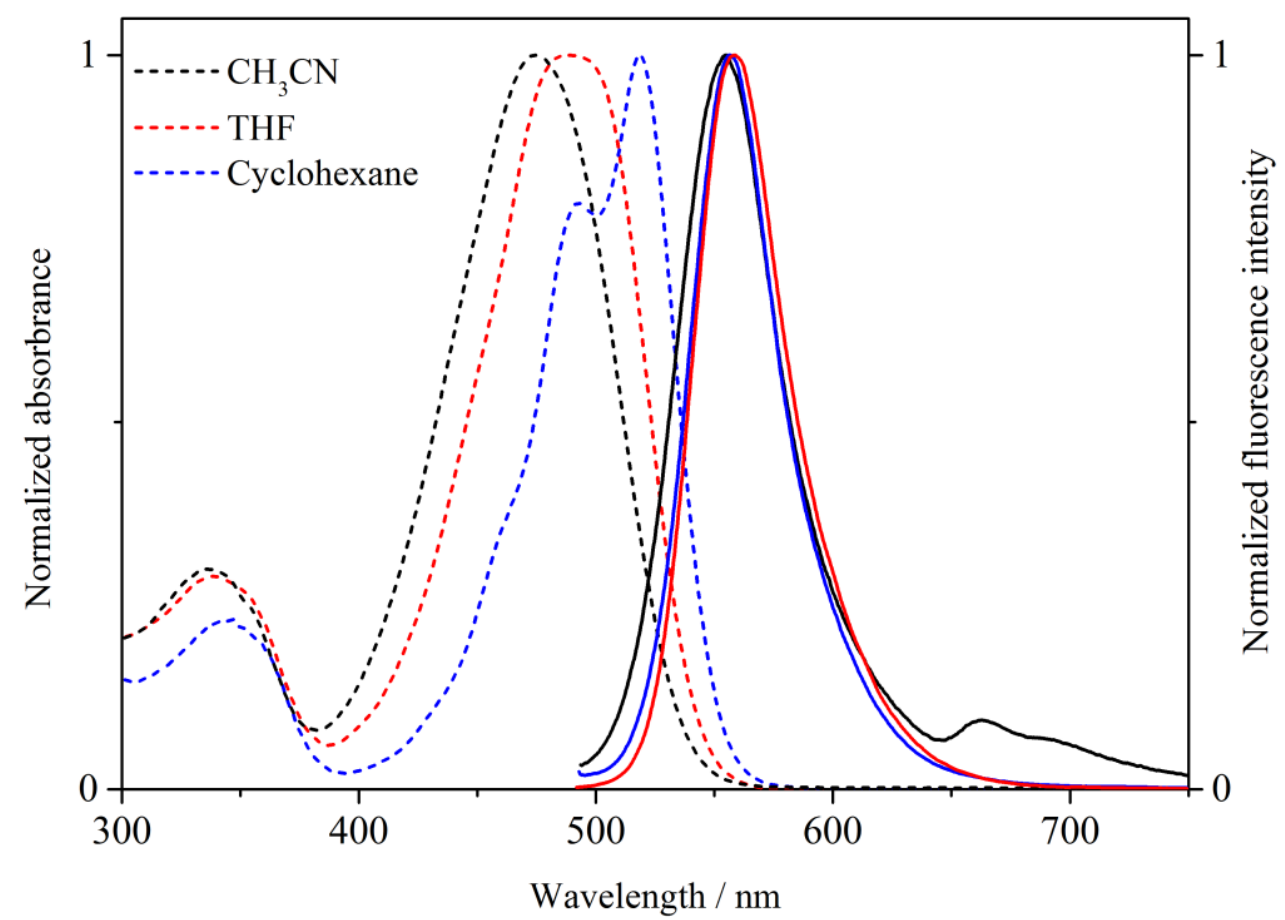

Fig. 3

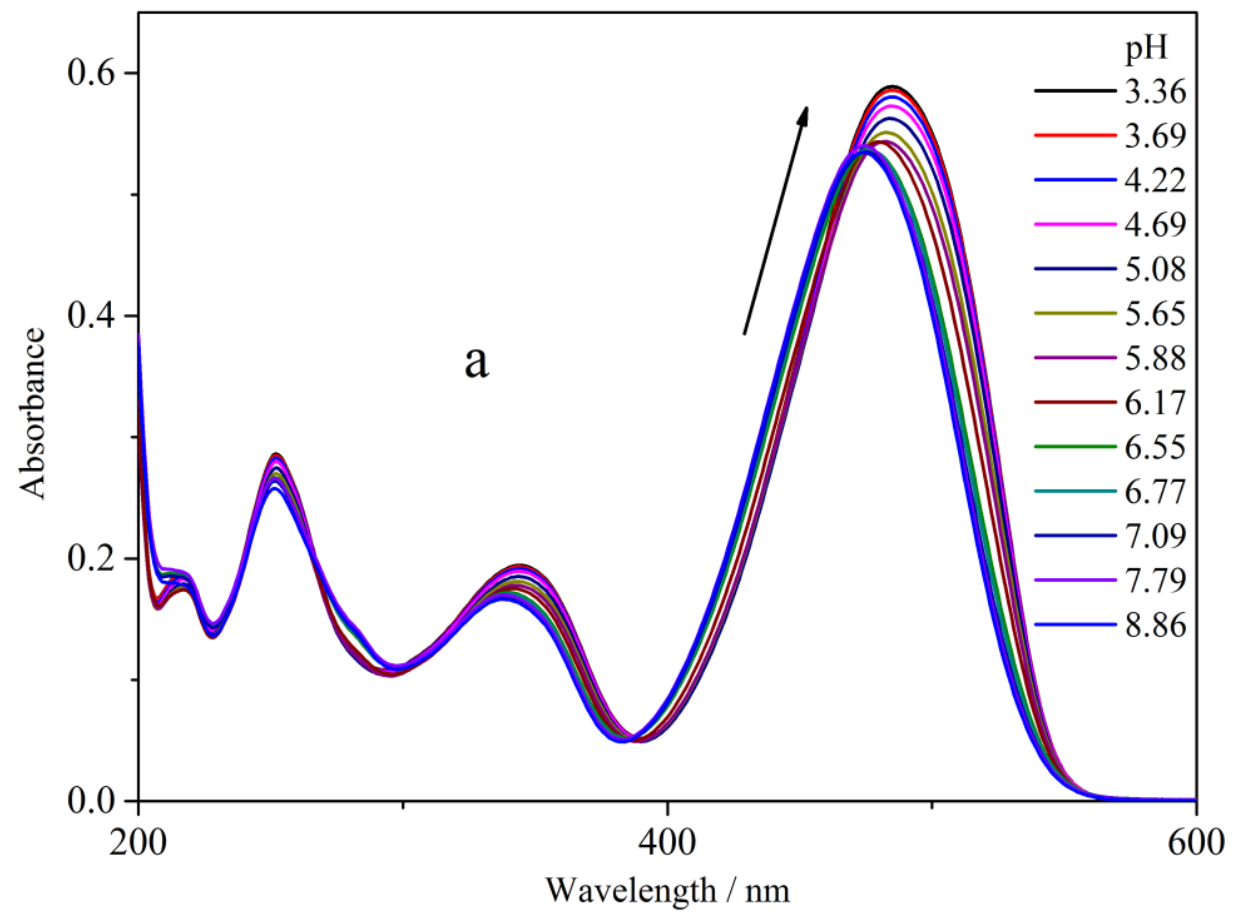



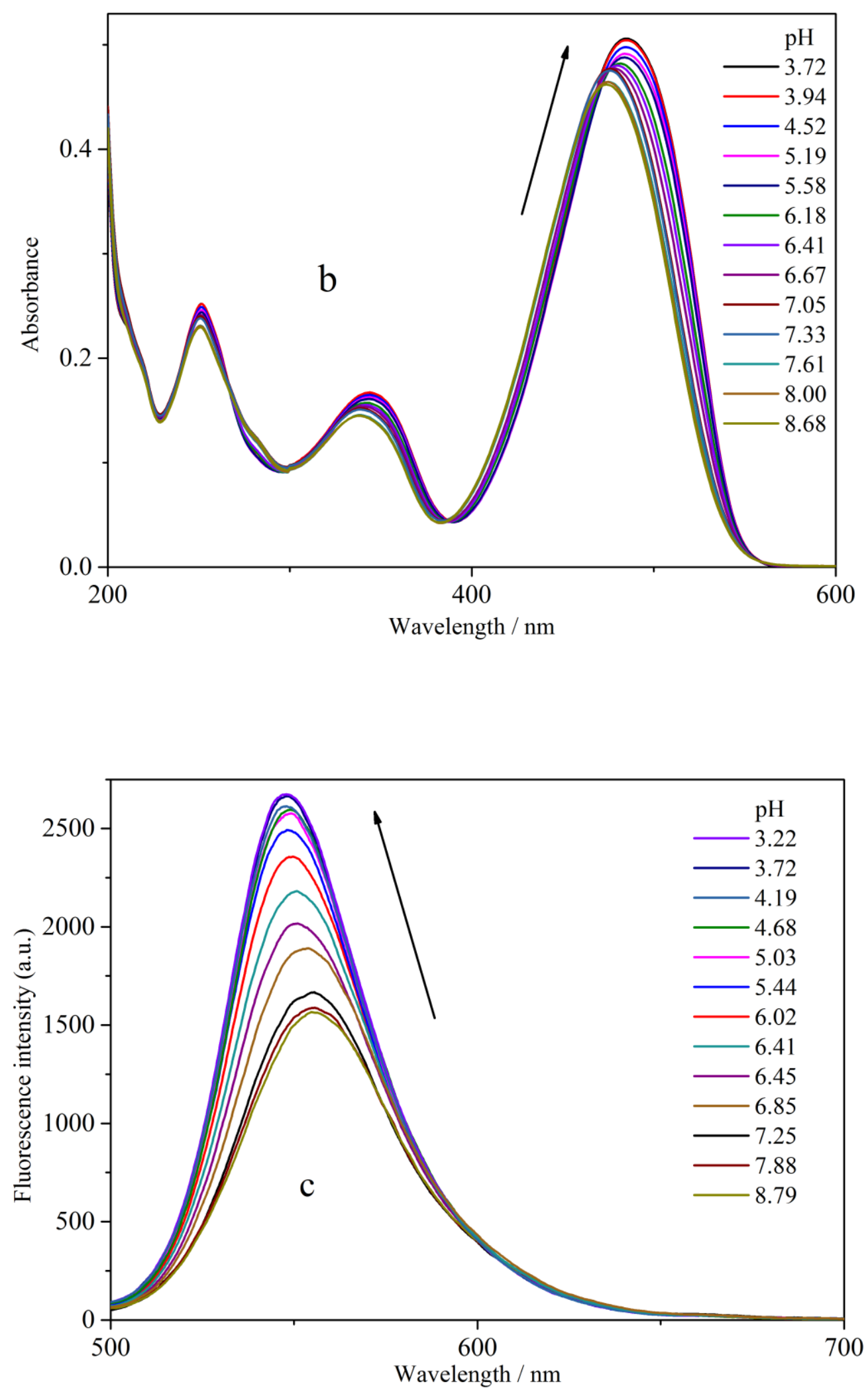


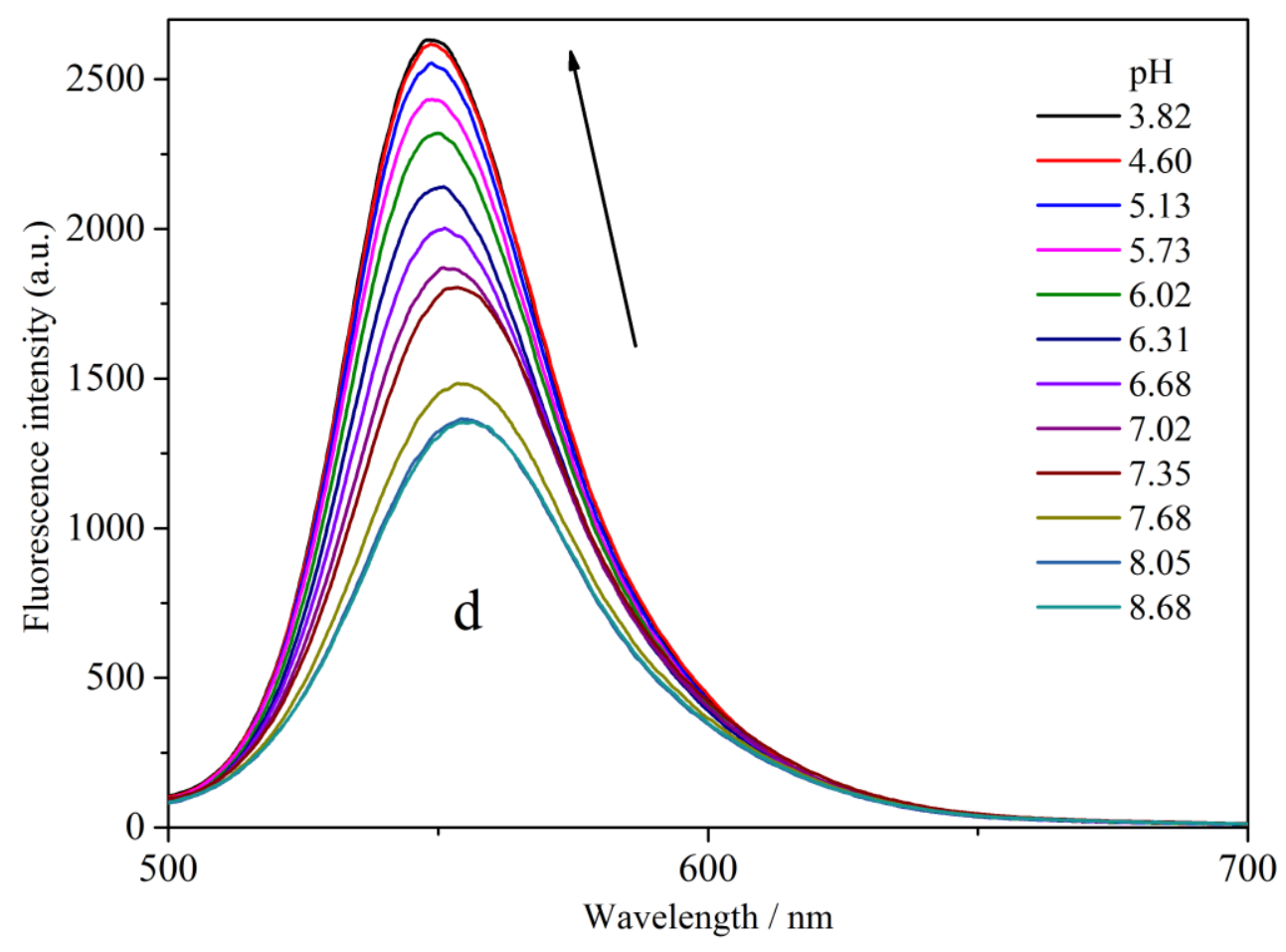

Fig. 4

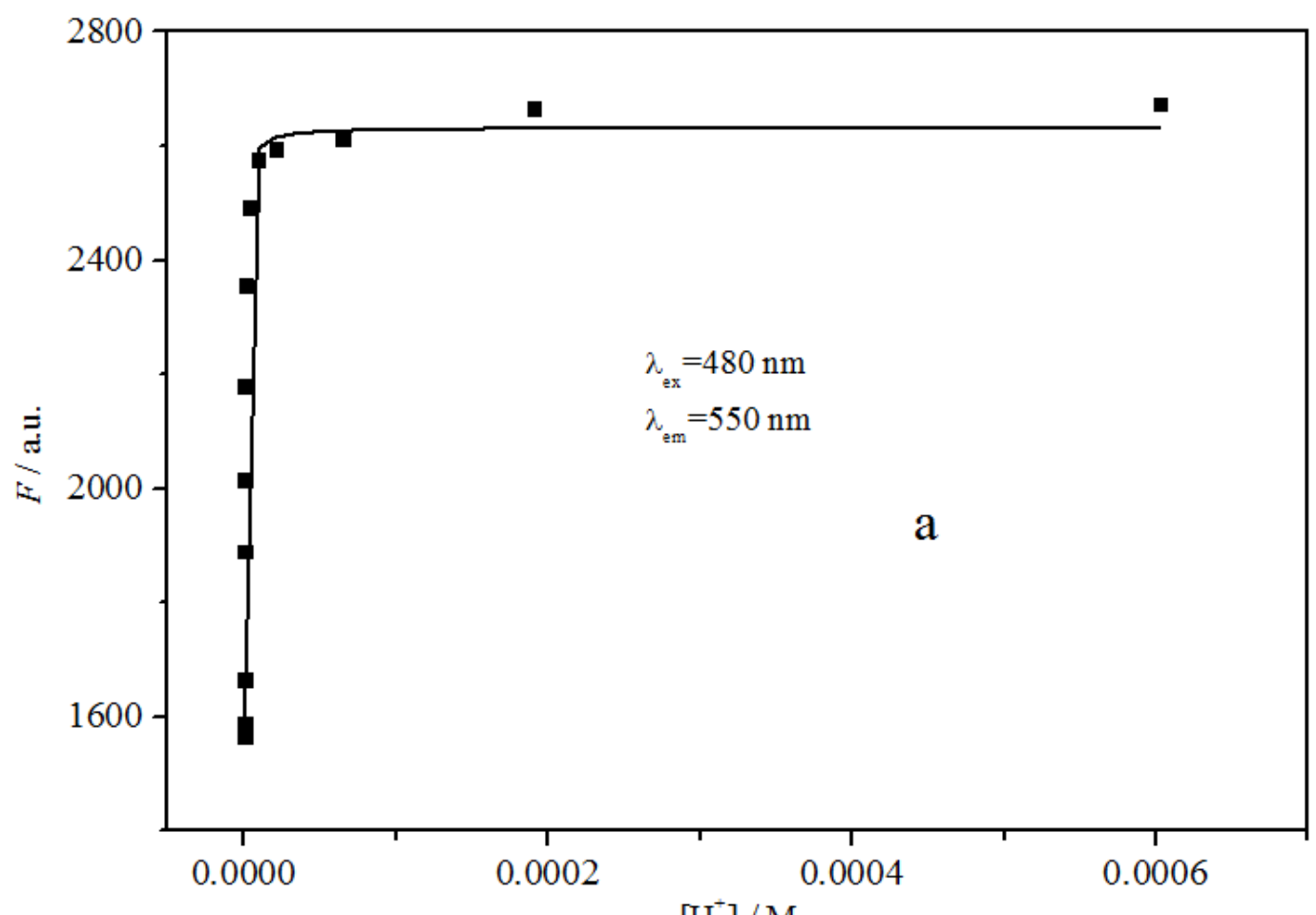

$\left[\mathrm{H}^{+}\right] / \mathrm{M}$ 


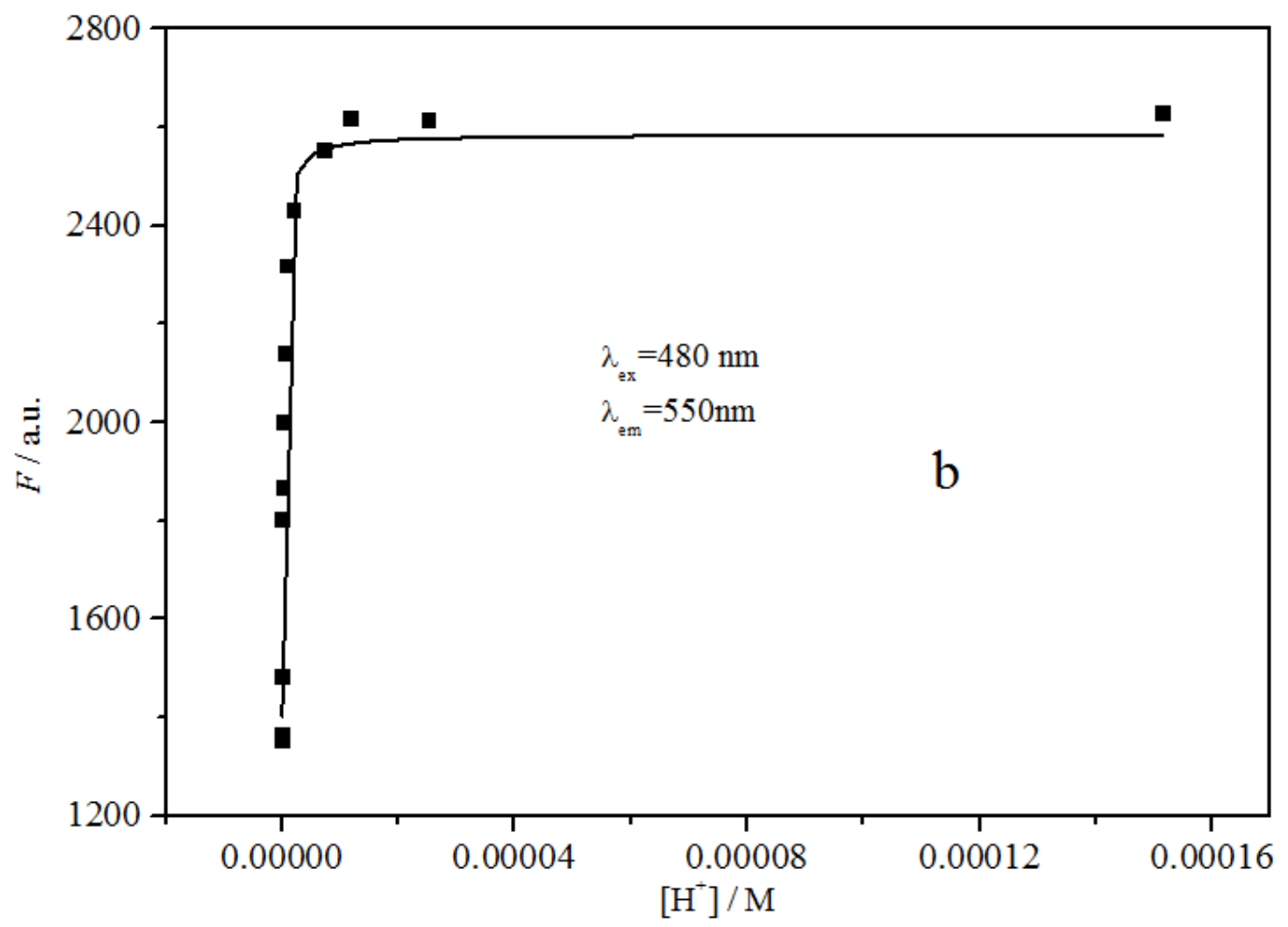

Fig. 5

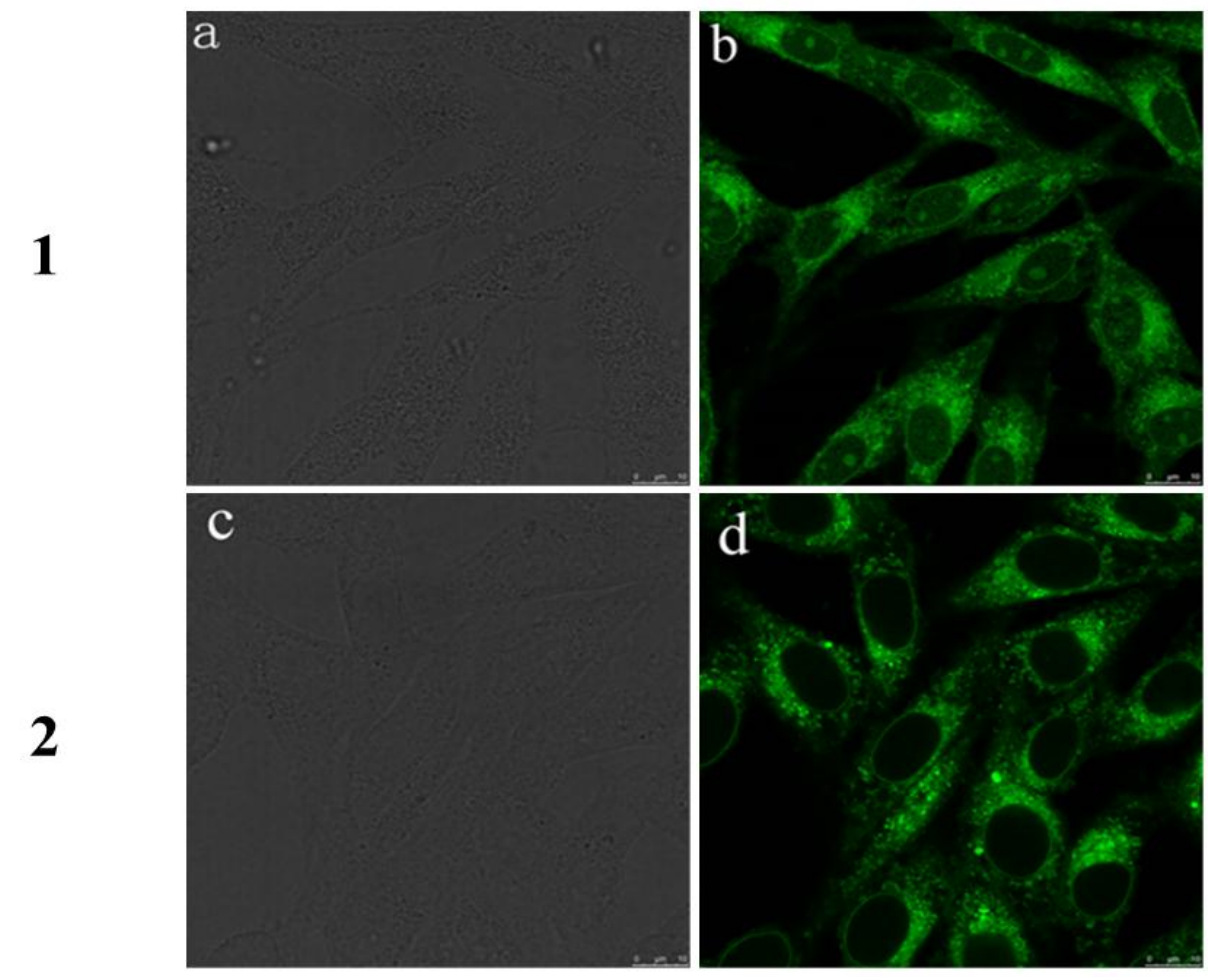


Table 1

\begin{tabular}{lcccccc}
\hline Solvent & $\lambda_{\text {abs }}(\max ) / \mathrm{nm}$ & \multicolumn{2}{c}{$\lambda_{\mathrm{em}}(\max ) / \mathrm{nm}$} & \multicolumn{2}{c}{$\Phi_{\mathrm{f}}$} \\
& $\mathbf{1}$ & $\mathbf{2}$ & $\mathbf{1}$ & $\mathbf{2}$ & $\mathbf{1}$ & $\mathbf{2}$ \\
\hline Cyclohexane & 518 & 518 & 557 & 557 & $0.055 \pm 0.001$ & $0.052 \pm 0.001$ \\
Toluene & 511 & 511 & 560 & 560 & $0.053 \pm 0.002$ & $0.057 \pm 0.002$ \\
Tetrahydrofuran & 488 & 486 & 557 & 550 & $0.046 \pm 0.001$ & $0.043 \pm 0.001$ \\
Dichloromethane & 489 & 486 & 556 & 553 & $0.052 \pm 0.002$ & $0.053 \pm 0.002$ \\
Dimethyl sulfoxide & 484 & 485 & 553 & 554 & $0.052 \pm 0.001$ & $0.049 \pm 0.002$ \\
Acetonitrile & 474 & 474 & 556 & 556 & $0.047 \pm 0.003$ & $0.055 \pm 0.001$ \\
\hline
\end{tabular}

\section{Scheme 1}<smiles></smiles>

$\mathrm{MeCN} / \mathrm{Et}_{3} \mathrm{~N}$ rt, $72 \mathrm{hrs}$

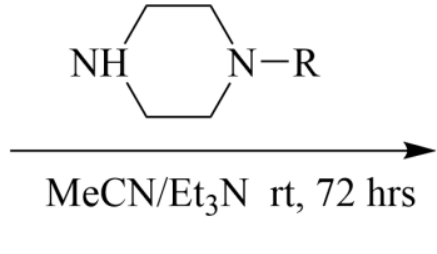<smiles></smiles>

1: $\mathrm{R}=\mathrm{CH}_{3}$ 2: $\mathrm{R}=\mathrm{CH}_{2} \mathrm{CH}_{3}$

a $a^{\prime}$ 


\section{Biographies}

Min Deng received her B.S. degree from Lanzhou University, PR China, in 2014. She is currently a master candidate at College of Chemistry and Chemical Engineering, Lanzhou University, PR China. Her research interests focus on developing fluorescent chemosensors.

Chengduan Yang received his B.S. degree from Weifang University, PR China, in 2013. He is currently a master candidate at College of Chemistry and Chemical Engineering, Lanzhou University, PR China. Her research interests focus on developing fluorescent chemosensors.

Deyan Gong received his B.S. degree from Xi'an University of Technology, PR China in 2014. He is currently a master candidate at College of Chemistry and Chemical Engineering, Lanzhou University, PR China. His research interests focus on developing fluorescent chemosensors.

Xiao-Liang Tang received his Ph.D. degree from Lanzhou University, PR China, in 2009. He is currently an associate professor at College of Chemistry and Chemical Engineering, Lanzhou University, PR China. His research interests focus on developing function materials and fluorescent chemosensors.

Wei-Sheng Liu received his Ph.D. degree from Lanzhou University, PR China, in 1996. He is currently a professor at College of Chemistry and Chemical Engineering, Lanzhou University, PR China. His research interests focus on developing function materials and fluorescent chemosensors.

Wen-Wu Qin received his Ph.D. degree from Lanzhou University, PR China, in 2003. 
He is currently a professor at College of Chemistry and Chemical Engineering, Lanzhou University, PR China. His research interests focus on developing fluorescent chemosensors 
Graphical Abstract

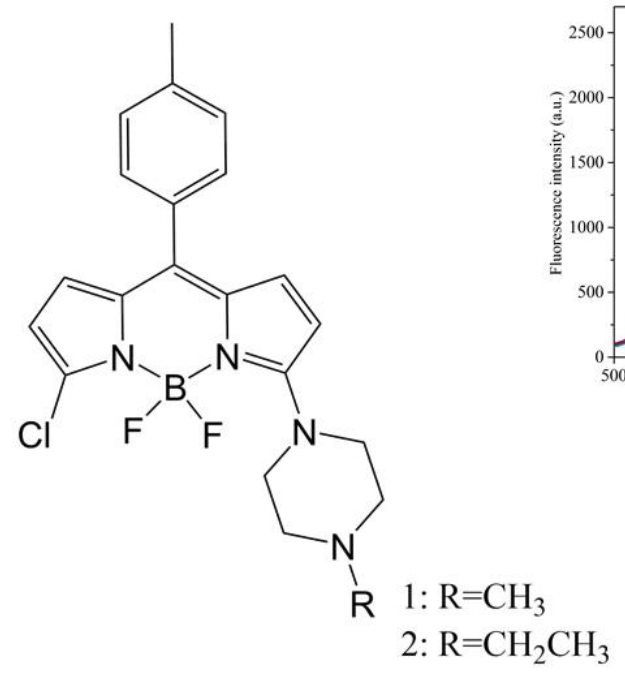

Sensors 1 and 2
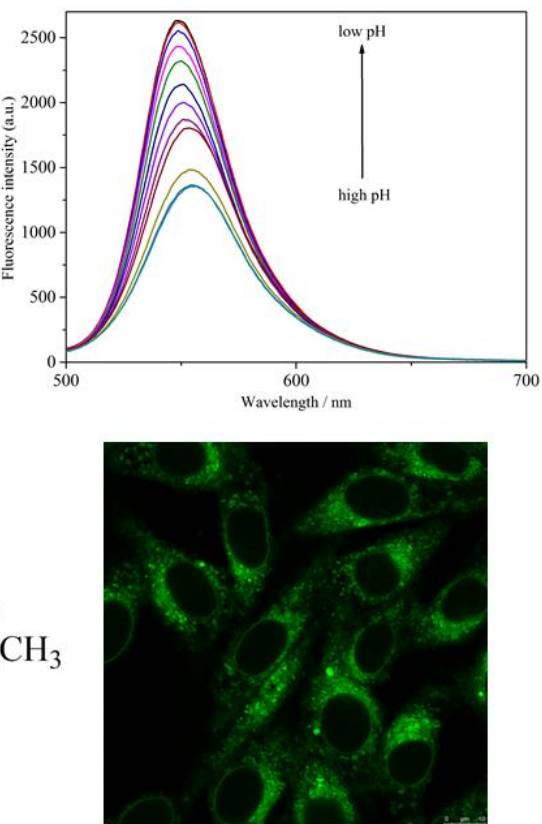